\title{
Language use statistics and prototypical grapheme colours predict synaesthetes' and non-synaesthetes' word-colour associations
}

\author{
Stephanie C. Goodhew* * Evan Kidd \\ Research School of Psychology, The Australian National University, Australia \\ ARC Centre of Excellence for the Dynamics of Language, Australia
}

\section{A R T I C L E I N F O}

\section{Article history:}

Received 23 March 2016

Received in revised form 1 October 2016

Accepted 13 December 2016

Available online 24 December 2016

\section{Keywords:}

Synaesthesia

Synesthesia

Language

Language statistics

Psycholinguistics

\begin{abstract}
A B S T R A C T
Synaesthesia is the neuropsychological phenomenon in which individuals experience unusual sensory associations, such as experiencing particular colours in response to particular words. While it was once thought the particular pairings between stimuli were arbitrary and idiosyncratic to particular synaesthetes, there is now growing evidence for a systematic psycholinguistic basis to the associations. Here we sought to assess the explanatory value of quantifiable lexical association measures (via latent semantic analysis; LSA) in the pairings observed between words and colours in synaesthesia. To test this, we had synaesthetes report the particular colours they experienced in response to given concept words, and found that language association between the concept and colour words provided highly reliable predictors of the reported pairings. These results provide convergent evidence for a psycholinguistic basis to synaesthesia, but in a novel way, showing that exposure to particular patterns of associations in language can predict the formation of particular synaesthetic lexical-colour associations. Consistent with previous research, the prototypical synaesthetic colour for the first letter of the word also played a role in shaping the colour for the whole word, and this effect also interacted with language association, such that the effect of the colour for the first letter was stronger as the association between the concept word and the colour word in language increased. Moreover, when a group of non-synaesthetes were asked what colours they associated with the concept words, they produced very similar reports to the synaesthetes that were predicted by both language association and prototypical synaesthetic colour for the first letter of the word. This points to a shared linguistic experience generating the associations for both groups.
\end{abstract}

(c) 2016 Elsevier B.V. All rights reserved.

\section{Introduction}

Synaesthesia is the neuropsychological phenomenon in which certain individuals have unusual sensory associations, such as seeing particular colours in response to particular words, associating shapes with tastes, or experiencing smells in response to sounds (Galton, 1880; Jones et al., 2011; Mattingley, Rich, Yelland, \& Bradshaw, 2001; Ramachandran \& Hubbard, 2001; Simner, Glover, \& Mowat, 2006a). While it was previously thought that the particular associations observed were arbitrary and idiosyncratic to particular synaesthetes, growing evidence suggests that there is some systematicity to the associations, grounded in associative and psycholinguistic processes. For example, it has been shown that high-frequency graphemes tend be associated with high-frequency colours (e.g., $a$ is more commonly associated with red than with other colours), whereas low-frequency graphemes tend to be associated with low-frequency colours (e.g., $q$ is more commonly associated with purple than with other colours) (Rich,

\footnotetext{
* Corresponding author at: Research School of Psychology (Building 39), The Australian National University, Canberra 2601, Australia.

E-mail address: stephanie.goodhew@anu.edu.au (S.C. Goodhew).
}

Bradshaw, \& Mattingley, 2005; Simner, 2007; Simner et al., 2006a; Simner et al., 2005). Here we studied lexical-colour synaesthesia, which allowed us to go beyond a simple frequency analysis such as that done with the grapheme-colour synaesthetes, and focus on the extent to which two words co-occur in language contributes to conceptcolour pairings. More specifically, the aim of this paper was to test whether language co-occurrence statistics, the degree to which a concept co-occurs with words that denote perceptual experience, could predict the particular lexical-colour associations reported by synaesthetes.

Synaesthesia is characterised by unusually dense and diffuse neural connections (Bargary \& Mitchell, 2008). One theory proposes that synchronous firing of cells representing the inducer (e.g., the word) and the concurrent (e.g., the colour) is integral to the development of synaesthetic associations (Brang, Hubbard, Coulson, Huang, \& Ramachandran, 2010; Brang, Rouw, Ramachandran, \& Coulson, 2011). The brain regions that process and represent visual form (including letters and words) and those which encode colour are adjacent to one another. This, coupled with the synaesthetes' enhanced neural connectivity, presents ample opportunity for such synchronous firing to occur and to solidify neural links between linguistic inducers and 
colour concurrents. It is perhaps unsurprising, therefore, that lexical-colour (in particular, weekday-colour) is among the most commonly experienced variants of synaesthesia (Simner et al., 2006b). Furthermore, some colours appear to have conceptual links in language: feeling a little blue, or green with envy. One possibility, therefore, is that the frequent co-occurrence of concepts and colours in the ambient language influence the specific word-colour association that synaesthetes develop. Such associations in language could create new or strengthen existing synaesthetic associations between words and colours via their repeated co-activation. Here we sought to test the influence of language association on the manifestation of adult synaesthetic associations for concept words.

In a related domain, it has been well documented that there is a general human tendency to map concepts in space. For example, we refer to a person who is happy as up, or someone who is sad as down. This suggests that emotional valence has a vertical mapping in space. Moreover, we describe looking forward to tomorrow and back in time, again implicating a directional component to mental representations of time (Boroditsky, Fuhrman, \& McCormick, 2011; Santiago, Lupianez, Perez, \& Funes, 2007; Weger \& Pratt, 2008). Such mental representations are often measured in the laboratory via conceptual cueing, which refers to the tendency for participants to respond more efficiently (quickly and accurately) to visual stimuli in particular spatial locations after being presented with particular concept words. For example, participants are quicker to respond to visual stimuli in the top part of the screen after the word sun or happy, and quicker to respond to visual stimuli in the bottom part of the screen after the word grass, or sad (Chasteen, Burdzy, \& Pratt, 2010; Dudschig, Souman, Lachmair, de la Vega, \& Kaup, 2013; Estes, Verges, \& Adelman, 2015; Estes, Verges, \& Barsalou, 2008; Gozli, Chasteen, \& Pratt, 2013; Gozli, Chow, Chasteen, \& Pratt, 2013b; Meier \& Robinson, 2004; Zwaan \& Yaxley, 2003). A growing body of work indicates that language association statistics predict the manifestation of particular spatial mappings of concepts (Goodhew, McGaw, \& Kidd, 2014; Hutchinson \& Louwerse, 2013; Louwerse, 2008; Louwerse \& Jeuniaux, 2010). Specifically, this means that the systematic co-occurrence of the words happy and up, for example, predict the upward shift of attention produced by the word happy. This has led to the suggestion that language association may actually causally create conceptual cueing (Goodhew et al., 2014). It is possible that such linguistically-based conceptual cueing effects could belong to a broader category of examples of how specific associations between stimuli derive from language exposure. From this perspective, we predicted that the specific perceptual mappings between inducers (words) and concurrents (colours) that synaesthetes experience would also be explained by systematic biases embedded in language. For example, synaesthetes might be more likely to see the word sorrow as blue if sorrow and blue co-occur frequently together in language.

The current study tested this possibility. Specifically, we assessed whether language co-occurrence statistics could explain the particular lexical-colour associations observed. We asked synaesthetes to report their colour experience in response to a standard set of conceptual cue items (Goodhew \& Kidd, 2016). This stimulus choice was made because if synaesthetic perceptual experiences are influenced by language, then words with stronger conceptual meaning (e.g., bliss, rather than Wednesday), which have been shown to have systematic associations with other perceptual dimensions (i.e., space), should be most conducive to revealing such an association. If language association between these concept words and colour words can predict the pairings for synaesthetes, then this supports this hypothesis that language can shape the manifestation of a broad array of human perceptual and cognitive mechanisms.

\section{Experiment $1 \mathrm{~A}$}

The purpose of Experiment 1A was to examine whether language association statistics could predict the specific word-colour pairings that synaesthetes reports.

\subsection{Method}

\subsubsection{Participants}

Thirty synaesthetes were recruited via online, newsletter, and newspaper advertisements and word-of-mouth. Their mean age was 30.6 years $(S D=15.2)$, and 25 were female and 5 male. Three reported being left-handed, and the other 27 right-handed. All participants provided written informed consent prior to participation.

All of the synaesthetes completed the online battery (Eagleman, Kagan, Nelson, Sagaram, \& Sarma, 2007) to verify their self-reported experiences of synaesthesia. Note that either grapheme-colour or lexicalcolour synaesthetes could experience colours in response to the conceptual cues. The battery does not have a broader category to identify lexical-colour synaesthetes, but instead seeks to identify the more common variants, such as those who experience colour in response to days of the week (e.g., Tuesday is orange), or months of the year (e.g., January is yellow). However, there is evidence that such forms of synaesthesia, which are the most common forms, relate to what could be considered 'overlearned' sequences (Barnett, Feeney, Gormley, \& Newell, 2009; Novich, Cheng, \& Eagleman, 2011), and can occur in the absence of other forms of synaesthesia (Simner et al., 2006b). In contrast, grapheme-colour synaesthesia is more likely to be related to lexical-colour synaesthesia. We were interested in synaesthetic colours elicited in response to the concept words. For this reason, we required participants to be verifiable grapheme-colour synaesthetes, and then explicitly asked synaesthetes what colours they experience or associate with a range of concepts, if any.

Specifically, we included for analysis synaesthetes who successfully passed the letter-colour subtest of the battery. Nineteen of the thirty self-reported synaesthetes met this classification requirement. All of these 19 synaesthetes had letter-colour consistency scores between 0 and $1.4(\mathrm{M}=0.68, \mathrm{SD}=0.22)$, which is the range indicative of synaesthesia (Rothen, Seth, Witzel, \& Ward, 2013). Appendix 1 provides comprehensive details on the forms of synaesthesia experienced by each participant.

\subsubsection{Apparatus and materials}

We sought to select target word stimuli that had strong and clear conceptual meanings and thus would have the greatest possibility of being systematically associated with colour words in language. Moreover, we reasoned that words that had clear and strong associations with another well-documented perceptual domain (i.e., vertical space) would be most likely to have such clear meaning and thus also be systematically associated with synaesthetic colours. Therefore, the words were selected from the recently-developed database of systematically rated items, called the Conceptual Cueing Database (Goodhew \& Kidd, 2016). Specifically, we selected 24 items with the most consistent up and down association ratings in the database, with the constraint that the items selected equally represented abstract and concrete items. Items associated with down had ratings between -0.98 and -1 , whereas positive items all had perfect +1 ratings. (This means that $98 \%$ and $100 \%$ of the participants involved in the rating validation study indicated that these items were associated with down, and 100\% of the participants indicated that items were associated with up, respectively). All 24 selected items can be seen in Table 1 .

\subsubsection{Procedure}

Synaesthetes were tested individually. They completed the synaesthesia battery on a laptop computer, and then completed a custom paper inventory that listed the 24 conceptual cue items on the left with space on the right for them to describe in writing the colours that they experienced in response to the items. They were asked to leave items blank if they did not experience a colour for that particular cue. 
Table 1

The 24 conceptual cues selected for the presented study from the conceptual cueing database (Goodhew \& Kidd, 2016).

\begin{tabular}{ll}
\hline Cues associated with up & Cues associated with down \\
\hline Bliss & Unhappy \\
Cheerful & Sorrow \\
Happy & Negative \\
Joy & Miserable \\
Victory & Doom \\
Positive & Bleak \\
Aircraft & Underground \\
Genius & Underworld \\
Peak & Grave \\
Sun & Mud \\
Star & Trash \\
Tower & Puddle \\
\hline
\end{tabular}

\subsection{Results}

In order to test whether patterns of language use could explain the specific concept-colour associations observed in our synaesthetes, we sought to compare synaesthetes' reported concept-colour pairings against language co-occurrence statistics. Synaesthetes' reported colour associations can be seen in Table 2, and from this it can be seen that there does appear to be some systematic clustering. Table 3 shows the most commonly selected colour for each item. In the tables we show absolute frequencies (i.e., the number of synaesthetes reporting each given association), however, for the purpose of analysis, these were converted to proportions of responses per colour. For example, since there were 109 total yellow associations, the 16 synaesthetes identifying cheerful as yellow would be a proportion of 0.15 (or 15\%).

\subsubsection{LSA}

We used latent semantic analysis (LSA) to quantify the associations between the concept and colour in language. LSA is a technique developed in computational linguistics, whereby words that regularly occur close together in speech and text are statistically grouped, under the
Table 3

Synaesthetes' most frequently-reported colour in response to each of the concept words.

\begin{tabular}{ll}
\hline Concept word & Most frequently associated colour \\
\hline Bliss & Pale blue \\
Cheerful & Yellow \\
Happy & Yellow \\
Joy & Yellow \\
Victory & White/red \\
Positive & Red/white \\
Aircraft & Red \\
Genius & Green \\
Peak & Yellow/green/orange/blue \\
Sun & Yellow \\
Star & Yellow \\
Tower & Yellow/blue \\
Unhappy & Yellow \\
Sorrow & Blue \\
Negative & Yellow/brown \\
Miserable & Blue \\
Doom & Black \\
Bleak & Grey \\
Underground & Brown \\
Underworld & Brown \\
Grave & Grey/brown/green \\
Mud & Brown \\
Trash & Green \\
Puddle & Brown \\
\hline
\end{tabular}

assumption that words that commonly occur adjacent or nearly adjacent to one another are close in meaning. It employs singular value decomposition to provide a metric of the relationship or similarity of meaning between concepts, which disregards word order and syntactic structure (Dumais, 2005; Landauer, Foltz, \& Darrell, 1998). The higher the value it produces the more frequently the two concepts are likely to occur together. Here, therefore, we used LSA similarity scores as a way of quantifying the association in language between the concept and colour words. Similarity scores (which range between -1 and +1 ) were obtained from the LSA pairwise comparison in term-to-term space. The topic space selected was general reading up

Table 2

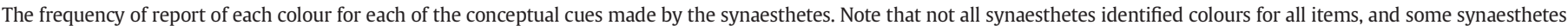

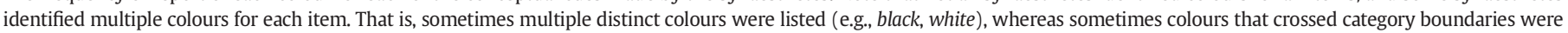

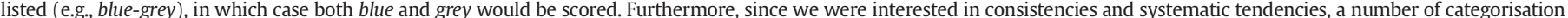

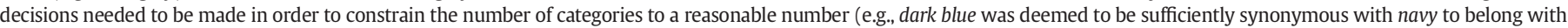

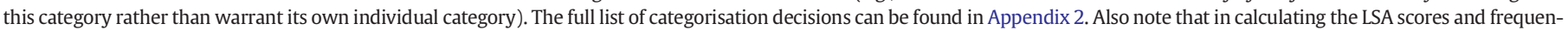
cies, we used the American spelling of gray, as this is the most common usage.

\begin{tabular}{|c|c|c|c|c|c|c|c|c|c|c|c|c|c|c|c|c|c|c|}
\hline & Cream & Yellow & Green & White & Brown & Orange & Black & Pale blue & Purple & Blue & Grey & Silver & Dark grey & Red & Dark blue & Gold & Dark red & Pink \\
\hline Bliss & & 3 & 2 & 4 & & 1 & 1 & 5 & 2 & 2 & 1 & & & 2 & 1 & & & 4 \\
\hline Cheerful & & 16 & 3 & 3 & & 3 & & & & 2 & & & & 2 & & & 1 & 2 \\
\hline Happy & & 9 & 4 & 1 & & 3 & 1 & & & 3 & & & & 5 & & 1 & & 1 \\
\hline Joy & & 6 & 4 & 3 & & 4 & & 1 & 2 & 3 & & & & 3 & & 2 & & 1 \\
\hline Victory & & 4 & 1 & 5 & 2 & 1 & 2 & & 3 & & 2 & 1 & & 5 & 2 & & 1 & 1 \\
\hline Positive & & 2 & 1 & 4 & & 1 & 2 & 1 & 1 & 3 & & & & 5 & & & & 1 \\
\hline Aircraft & & 2 & 3 & 3 & & 1 & 1 & 2 & 1 & 4 & 2 & & & 5 & 1 & & & \\
\hline Genius & 1 & 3 & 9 & 2 & 4 & & 3 & & 2 & 2 & 2 & 1 & & 2 & & 1 & & 1 \\
\hline Peak & & 5 & 4 & 1 & 1 & 4 & 2 & & 2 & 4 & 1 & & & 2 & 1 & & & 2 \\
\hline Sun & & 13 & 1 & & 1 & 2 & 2 & & & 1 & & & & 4 & & 1 & & 1 \\
\hline Star & & 7 & 1 & 5 & & 3 & 3 & & & 5 & & 2 & & 2 & 1 & & & 2 \\
\hline Tower & 1 & 5 & 3 & 2 & 3 & 1 & 2 & 1 & 2 & 5 & 4 & & & & & & & \\
\hline Unhappy & & 5 & 4 & & 4 & 1 & 1 & & 1 & 4 & 5 & & 1 & 1 & 1 & & & 1 \\
\hline Sorrow & & 4 & 1 & 2 & 2 & & 3 & & & 6 & 2 & & 2 & 3 & 3 & & 1 & 1 \\
\hline Negative & 2 & 4 & 3 & 1 & 4 & 1 & 6 & & & 2 & 3 & 1 & & 4 & & & 1 & 2 \\
\hline Miserable & 1 & 1 & 2 & 2 & 4 & 2 & 3 & & 1 & 5 & 2 & & 1 & 2 & 3 & & 2 & 1 \\
\hline Doom & & 1 & & 2 & 5 & 1 & 10 & & 1 & 3 & 2 & & & 1 & 2 & & 2 & \\
\hline Bleak & 1 & 3 & 3 & 2 & 1 & 1 & 1 & 1 & 2 & 5 & 7 & & & 1 & 1 & & & 2 \\
\hline Underground & 1 & 3 & 4 & 1 & 11 & & 4 & & 1 & 1 & 2 & & 1 & 1 & 1 & & & 1 \\
\hline Underworld & 1 & 3 & 3 & 1 & 6 & & & & & 3 & 2 & & & 1 & 2 & & 1 & 1 \\
\hline Grave & & 2 & 6 & & 6 & & 2 & & 2 & 2 & 8 & 1 & 1 & & 1 & & & \\
\hline Mud & & 1 & 2 & & 14 & 1 & 1 & & & 1 & & & & 1 & 1 & & 2 & 1 \\
\hline Trash & 1 & 4 & 6 & & & & 2 & & 1 & 3 & 3 & & 1 & & 1 & & 1 & 1 \\
\hline Puddle & 2 & 3 & 4 & & 12 & 1 & 1 & & 2 & 4 & 2 & & & 1 & 2 & & & \\
\hline
\end{tabular}


to a 1-year college level, using the maximum number of factors available (see http://lsa.colorado.edu/).

\subsubsection{Additional variables}

Several control measures were included for the concept word cues, so as to mitigate against the possibility that any relationship between LSA scores and participants' concept-colour matching could be explained by simple properties of the concept word only. These variables were: (i) (log transformed) word frequency, (ii) imageability, and (iii) age of acquisition. Log transformed concept word frequency was calculated using Google Ngram (Michel et al., 2011), which is large, publicly searchable corpus. We set Google Ngram to calculate the (case-insensitive) concept frequencies over the most recent 10 years available from the database (1998-2008), with a smoothing of 10 to yield the average collocation across the 10 most recent years of the corpus. The log frequencies of each of the concept words can be found in Appendix 4. Imageablity (i.e., the degree to which a word is rated as concrete or abstract) ratings were taken from (Brysbaert, Warriner, \& Kuperman, 2014). Age of acquisition ratings were taken from (Kuperman, Stadthagen-Gonzalez, \& Brysbaert, 2012).

Finally, we also wanted to analyse how the prototypical graphemecolour pairings that grapheme-colour synaesthetes experience may have influenced concept-colour pairings. That is, as mentioned earlier, there are prototypical colours that grapheme-colour synaesthetes see for given letters (e.g., $a$ is red, $b$ is blue or brown, $c$ is yellow or pink, etc.) (Simner, 2007). It is possible that our participants' concept-colour pairings could be influenced by these pairings (e.g., the fact that $c$ is typically yellow could have led to the word cheerful being associated with yellow most often). To test for this, we included a variable that coded for congruency between a given concept-colour association and the prototypical colour for the first letter of the concept word. For example, this means that the cheerful-yellow association would be coded as congruent (because $c$ is typically yellow), whereas the sorrow-blue association would be coded as incongruent (because $s$ is typically red or yellow, not blue).

\subsubsection{Analysis}

To examine whether language-use predicted the frequency with which synaesthetes selected particular colours as associated with given concept words, we firstly selected for analysis the colour dimensions which had 10 or more responses associated with them. That is, there were 10 or more responses that identified this colour as associated with given concept words. These were: yellow, green, white, brown, orange, black, purple, blue, grey, red, navy, and pink (whereas cream, pale blue, silver, dark grey, gold, and dark red were excluded). This cut-off was applied to ensure that there was sufficient variation along the colours included in the analysis, and had the secondary benefit of excluding six colours which are absent from the prototypical grapheme-colour alphabet. We aimed to test whether LSA statistics predicted participants' concept-colour associations controlling for the frequency, age of acquisition, and imageability of the concept words, and lexicalcolour synaesthetes' prototypical grapheme-colour associations. We analysed the data using linear mixed effects modelling in $\mathrm{R}$ (version 3.2.2 R Development CoreTeam), which were calculated using the lme4 package (version 1.1-8, Bates \& Maechler, 2010). LSA, log transformed concept word frequencies, age of acquisition, concreteness, and first-letter prototypical colour congruency were fixed effects, and word and reported colour were random effects. Simple bivariate correlations between the continuous variables are reported in Appendix 5. All continuous variables were zero-centred to reduce any effect of collinearity. All variables were normally distributed, except for age of acquisition. Efforts to transform this variable proved futile, and so the raw values were retained for the analysis. Grapheme-colour congruency was sum coded (congruent $=0.5$, incongruent $=-0.05$ ) to allow ANOVA-like interpretations of effects (Linck \& Cunnings, 2015). Because the dependent measure was proportion we transformed it using a logit transformation (i.e., $y^{\prime}=\ln [(y+c) /(1-y)]$ ), where $\ln$ is natural logarithm, $y$ represents the original DV value, and $c$ represents a constant added to account for zero values. ${ }^{1}$

Since we had five independent variables and only 288 observations we had to be conservative in our statistical modelling. Our hypothesis was that LSA estimates of concept-colour association would predict participants' ratings, but grapheme-colour congruency has also been shown to predict synaesthetes' perceptual experiences. We therefore entered the factorial combination of these two variables into the model (i.e., main effects and their interaction), but only entered the remaining control variables as main effects. Random intercepts for concept and colour were included to control for by-colour and by-concept variability. Following Barr, Levy, Scheepers, and Tily (2013) we specified a maximal random effects structure. ${ }^{2}$ The full maximal model failed to converge. Random slopes were removed one at a time; however, the model only converged when all were removed. Table 4 reports the results from the analysis.

Table 4 shows three notable results. Firstly, as predicted, LSA positively predicted synaesthete's concept-colour matchings, such that higher associations between a concept and a colour as measured by LSA predicted higher concept-colour matching by participants. Secondly, grapheme-colour congruency also predicted concept-colour matching, such that synaesthetes were more likely to choose colours for concepts based on biases deriving from the concept's first letter. Thirdly, there was a significant LSA by grapheme colour congruency interaction. This interaction is plotted in Fig. 1A, showing that the effect of grapheme-colour congruency becomes larger as LSA colour-concept estimates become larger. Finally, there was a significant effect of age of acquisition, which showed that concept-colour matchings became stronger with later acquired words.

\subsection{Discussion}

As hypothesised, the results revealed that language-association scores (as operationalised by LSA) significantly predicted synaesthetes' reports of their concept-colour associations. This means that systematic semantic association between a concept word (e.g., sorrow) and a colour word (e.g., blue) predicted the colour that participants reported in response to the concept words (e.g., sorrow = blue). Furthermore, consistent with previous research, the prototypical synaesthetic colour for the first letter of each concept word also influenced the colours that synaesthetes reported in response to the concept words. This means, for example, that the fact that the letter ' $s$ ' is often yellow for grapheme-colour synaesthetes predicted the fact that participants reported the colour yellow in response to words such as sun and star. These two variables also interacted, which means that whether or not the colour reported for particular concept words was predicted by the relationship between the first letter of the word and the prototypical grapheme-colour alphabet depended on the association in language between the given concept and colour word. The nature of this relationship was such that the effect of grapheme-colour congruency increased as LSA scores increased. Age of acquisition was also a reliable predictor of concept-colour pairings in its own right, further supporting the notion that language exposure creates reliable systematicities in concept-colour pairings. In Experiment 1B, we sought to examine whether non-synaesthete controls would report similar or different concept-colour associations.

\footnotetext{
${ }^{1}$ Results did not change when the data were analysed using the transformed or untransformed data.

${ }^{2}$ In this instance, maximal structure meant random slopes for all fixed effects, but not the interaction between LSA and Grapheme-Colour Congruency, since the latter is a between-item variable.
} 
Table 4

Liner mixed effects models predicting synaesthetes' concept-colour frequency reports * $p<0.05$. For model code see Appendix 6 .

\begin{tabular}{llll}
\hline & $\beta$ & $\mathrm{SE}(\beta)$ & $t$ \\
\hline Intercept & 0.08 & 0.004 & 18.45 \\
LSA & 0.102 & 0.047 & $2.16^{*}$ \\
Grapheme-colour congruency & 0.04 & 0.011 & $3.3^{*}$ \\
Log frequency & 0.001 & 0.008 & 0.08 \\
Age of acquisition & 0.004 & 0.002 & $2.01^{*}$ \\
Imageability & -0.0007 & 0.004 & -0.19 \\
LSA * Grapheme-colour congruency & 0.34 & 0.14 & $2.40^{*}$ \\
\hline
\end{tabular}

\section{Experiment 1B}

The purpose of Experiment 1B was to assess the concept-colour associations reported by non-synaesthete controls. In previous research, it has been shown that when non-synaesthetes are asked to generate representative colours for graphemes, the colours they choose tends to mimic synaesthetes' perceptual experience of colour in response to graphemes, such as $y$ being yellow, and $d$ being brown (Rich et al., 2005; Simner et al., 2005). This suggests that early learning experiences common to both synaesthetes and non-synaesthetes shape these associations, but that the association has a distinct perceptual nature for synaesthetes (Rich et al., 2005). Here we wanted to see whether such similarities across

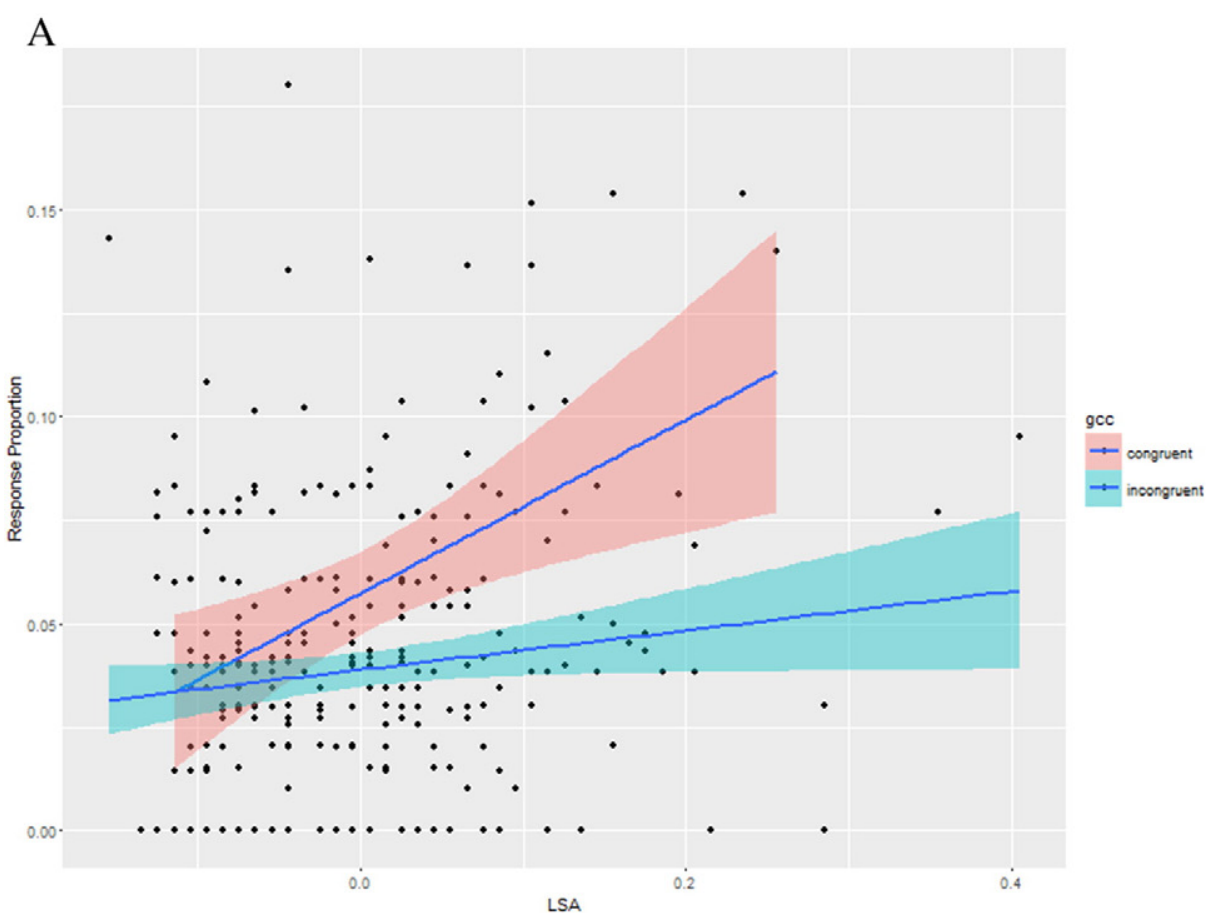

B

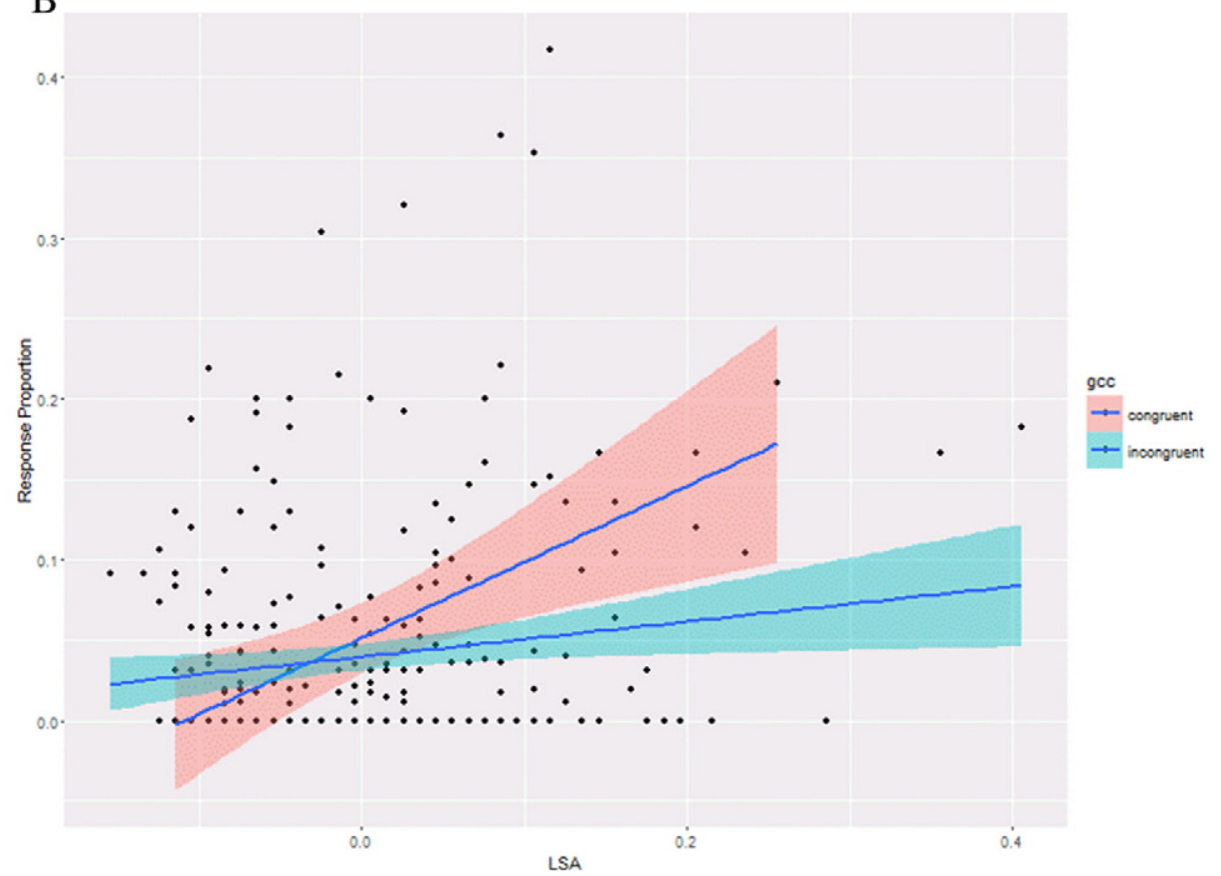

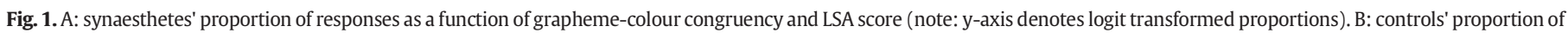
responses as a function of grapheme-colour congruency and LSA score (note: y-axis denotes logit transformed proportions). 
synaesthetes and non-synaesthetes were also observed for concept-colour pairings.

\subsection{Participants}

Twenty-five non-synaesthetes were recruited via online advertisements and word-of-mouth. Their mean age was 21.37 years (SD = 2.87), and 18 were female and 7 were male. Two reported being lefthanded, and the rest right-handed. All participants provided written informed consent prior to participation.

We took steps to ensure that the participants in this experiment were not synaesthetes but non-synaesthete controls. Of the 25 total participants, 22 completed the online battery for this purpose (Eagleman et al., 2007), while another three were tested while the website for the battery was non-functional for several days and so these participants instead completed a paper-and-pencil measure that asked equivalent screening questions. Altogether, the battery only identified one participant as a synaesthete (taste-colour, temperature-colour, and visiontaste), and so this participant was removed from the analysis. Two others were identified as having absolute/perfect pitch (which is often associated with synaesthesia but not actually a form of synaesthesia itself), and so they were retained for analysis.

\subsection{Apparatus and materials}

These were identical to Experiment 1A.

\subsection{Procedure}

Participants were tested individually. They completed the synaesthesia battery on a laptop computer, and then completed a custom paper inventory that listed the 24 conceptual cue items on the left with space on the right for them to describe in writing the colours that they associate or imagine in response to the items. They were asked to leave items blank if they did have any colour to report for that particular cue. Below, Table 5 shows the frequency of report of each colour for each of the conceptual cues. Table 6 shows the most frequently reported colour for each item.
Table 6

Non-synaesthetes' most frequently-reported colour in response to each of the concept words.

\begin{tabular}{ll}
\hline Concept word & Most frequently associated colour \\
\hline Bliss & Pink/blue \\
Cheerful & Yellow \\
Happy & Yellow \\
Joy & Yellow \\
Victory & Red \\
Positive & Green \\
Aircraft & White \\
Genius & Green \\
Peak & White \\
Sun & Yellow \\
Star & White \\
Tower & Grey \\
Unhappy & Blue \\
Sorrow & Black/blue \\
Negative & Black \\
Miserable & Grey \\
Doom & Black \\
Bleak & Grey \\
Underground & Brown/black \\
Underworld & Black \\
Grave & Grey \\
Mud & Brown \\
Trash & Green \\
Puddle & Brown \\
\hline
\end{tabular}

\subsection{Results E' discussion}

To examine whether language-use predicted the frequency with which controls selected particular colours as associated with given concept words, we firstly selected for analysis the colour dimensions which had 10 or more responses associated with them as per Experiment 1A. Our statistical analyses strategy was also the same as in Experiment 1A: the factorial combination of LSA and grapheme-colour correspondence were entered into the model, and age of acquisition, imageability, and log frequency were entered as main effects. The most maximal model that converged had random intercepts for concept and colour, by-concept and by-colour random slopes for grapheme-colour correspondence and by-concept

Table 5

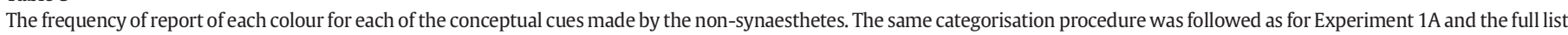
of categorisation decisions can be found in Appendix 3. Also as per Experiment 1A, these absolute frequencies were converted to proportions of responses per colour for analysis.

\begin{tabular}{|c|c|c|c|c|c|c|c|c|c|c|c|c|c|c|c|c|c|c|}
\hline & Cream & Yellow & Green & White & Brown & Orange & Black & Pale blue & Purple & Blue & Grey & Silver & Dark grey & Red & Dark blue & Gold & Dark red & Pink \\
\hline Bliss & 2 & 4 & 3 & 2 & & 3 & & 3 & 1 & 5 & & & & 2 & & & 1 & 5 \\
\hline Cheerful & & 18 & 1 & & & 3 & & & & & & & & 3 & & & & 2 \\
\hline Happy & & 13 & 4 & 1 & & 1 & & & & 1 & & & & 2 & & 1 & 1 & 2 \\
\hline Joy & 2 & 9 & & 2 & & 4 & & 1 & & 1 & & 1 & & 4 & & & & 2 \\
\hline Victory & & 3 & 1 & & & 3 & & & & & & 1 & & 9 & 2 & 3 & 1 & 1 \\
\hline Positive & & 5 & 6 & 3 & & 2 & & & & 3 & & & & 5 & & & & \\
\hline Aircraft & 1 & & & 17 & & & & & & 4 & 6 & & & & & & & \\
\hline Genius & & 1 & 5 & & & 1 & 2 & & 2 & 3 & 1 & & & 2 & & & & \\
\hline Peak & & 1 & 1 & 6 & 4 & & 3 & & 2 & 4 & 3 & & & & & & & \\
\hline Sun & & 19 & & 3 & & 8 & & & & & & & & 1 & & & & \\
\hline Star & & 9 & & 12 & & & 2 & & & 2 & 1 & 4 & & & & 1 & & \\
\hline Tower & & & & 2 & 4 & & 3 & & & & 13 & 2 & & 2 & & & 1 & \\
\hline Unhappy & & & & & & & 6 & & & 10 & 6 & & 1 & & 4 & & & \\
\hline Sorrow & & 1 & 1 & & 1 & & 7 & 1 & 1 & 7 & 5 & & 1 & & 1 & & 1 & \\
\hline Negative & & & & 1 & & & 11 & & 2 & 1 & 3 & & & 5 & 1 & & 1 & \\
\hline Miserable & & & & & & & 5 & & 2 & 5 & 9 & & 2 & & 2 & & & \\
\hline Doom & & & & 1 & & & 11 & & & & 6 & & 1 & 3 & & & 2 & \\
\hline Bleak & 1 & & 1 & 2 & & & 4 & & & & 10 & & & & & & & \\
\hline Underground & & 1 & & & 10 & & 10 & & & & 3 & & 1 & & & & & \\
\hline Underworld & & 2 & & 1 & 5 & & 11 & & & 1 & 4 & & & 7 & 1 & & 2 & \\
\hline Grave & & & 1 & 1 & 6 & & 4 & & & & 13 & & & 1 & & & & \\
\hline Mud & & & & & 24 & & & & & & & & & 1 & & & & \\
\hline Trash & & & 7 & 1 & 4 & & 5 & & & 1 & 7 & & & & & & & \\
\hline Puddle & & & 1 & 1 & 10 & & 1 & 2 & & 4 & 6 & & & & & & & \\
\hline
\end{tabular}


Table 7

Liner mixed effects models predicting non-synaesthetes' concept-colour frequency reports. ${ }^{*} p<0.05$. For model formula, see Appendix 6.

\begin{tabular}{llll}
\hline & $\beta$ & $\mathrm{SE}(\beta)$ & $t$ \\
\hline Intercept & 0.08 & 0.01 & $8.6^{*}$ \\
LSA & 0.28 & 0.11 & $2.46^{*}$ \\
Grapheme-colour-congruency & 0.03 & 0.03 & 0.944 \\
Log frequency & 0.017 & 0.02 & 0.946 \\
Age of acquisition & 0.001 & 0.00 & 0.25 \\
Imageability & -0.01 & 0.01 & -1.37 \\
LSA * Grapheme-colour congruency & 0.70 & 0.32 & $2.22^{*}$ \\
\hline
\end{tabular}

random slopes for LSA, age of acquisition, and imageability. The results are reported in Table 7.

Table 7 shows that, like the synaesthetes in Experiment 1A, LSA significantly predicted the control participants' concept-colour matching, such that more highly associated concept-colour pairings were more likely to be reported. Unlike in Experiment 1A, grapheme-colour congruency and age of acquisition did not predict colour-concept matching. However, as in Experiment $1 \mathrm{~A}$, there was a significant LSA by grapheme-colour congruency interaction. Fig. 1B plots the interaction, showing that as the strength of the association between concept and colour (as measured by LSA) becomes stronger, the effect of grapheme-colour consistency becomes stronger.

Finally, we investigated whether there were any substantial statistical differences between the two groups (synaesthetes versus controls) by comparing them in one overall analysis. We used the same analysis strategy as before, but added group as a between-participants variable. Specifically, the factorial combination group, LSA, and grapheme-colour congruency were entered into the model, as were main effects of age of acquisition, imageability, and log word frequency. Despite the fact that there were minor differences across the two groups, there were no significant interactions with group. There were only two significant model terms: (i) a significant positive effect of LSA on concept colour matchings $(\beta=0.35, \operatorname{SE}(\beta)=0.102, t=3.43, p<0.05)$, and (ii) a significant LSA by grapheme-colour congruency interaction $(\beta=0.80, \operatorname{SE}(\beta)=0.22, t=$ $3.52, p<0.05)$. The full model output is shown in Appendix 7. This suggests that the concept-colour pairings were similar for synaesthetes and controls, such that both language use patterns relating the concepts to colours as well as the typical colour associated with starting letter of each concept word predict these associations for both groups. Moreover, the predictive value of each variable (LSA versus grapheme-colour congruency) increases as score on the other variable increases for both groups. This indicates that they are interrelated.

\section{General discussion}

The present study demonstrated that both language association statistics and the prototypical colour associated with the first letter of the word reliably predicted synaesthetes' and controls' concept-colour associations, and also interacted such that as values on LSA increased, so did the impact of grapheme-colour congruency. The fact that LSA was predictive in its own right is consistent with the broad conclusions from previous research implicating a psycholinguistic basis to synaesthesia (Simner, 2007), but it is also novel in that it is the first to demonstrate that language association statistics play a key role in explaining the observed associations. That is, rather than the observation that high-frequency graphemes tend to be paired with high-frequency colours (Simner et al., 2005), here we showed that the systematic relationship between concept words and colours influenced the manifestation of specific inducer-concurrent pairings in synaesthesia. This means that, for example, the fact that synaesthetes are most likely to associate happy with yellow is predicted by the fact that happy and yellow co- occur together in language more often than would be expected by chance. Similarly, synaesthetes are more likely to associate sorrow with blue, for which there is also linguistic evidence in the ambient language. Furthermore, the fact that the same pattern of associations was observed for the non-synaesthetes controls suggests that the associations for both groups may emerge from a shared linguistic experience. The difference is that this results in a perceptual experience for synaesthetes, whereas it is more of a cognitive association for non-synaesthetes. Of course, here we have simply measured language associations, and therefore can only speculate about what causal role exposure to regularities in language may play in the development of these associations: it could equally be the case that another factor is responsible for creating both the concept-colour pairings and the language associations. But if language is not shaping our basic cognition and perception, then at the very least, it is an intricate and insightful reflection of these processes.

The other interesting result here was that the colour that is typically associated with the first letter of each of the concept words also predicted the colour that participants were likely to report for the word, and this was particularly true when LSA scores for a given concept-colour pairing were high. This means, for example, that participants were most likely to associate the word genius with the colour green was predicted by the fact that green is one of the two prototypical colours for the letter $g$, but only to the extent that 'genius' and 'green' tended to be associated in language according to LSA. The fact that first grapheme colour was important in explaining concept-colour pairings is consistent with previous research indicating that the first letter of a word plays a role in shaping the synaesthetic colour experience for the whole word. For example, in one report, coloured hearing (speech perception) for nine synaesthetes tended to be based on graphemes rather than lexemes (Baron-Cohen, Harrison, Goldstein, \& Wyke, 1993), and for another seven synaesthetes who experience colour in response to linguistic stimuli, there were systematic relationships between the colours generated by words and those generated by the graphemes (Ward, Simner, \& Auyeung, 2005). Furthermore, in one individual, linguistic subcomponents of words, such as word stress and letter position influenced the colours experienced (Simner et al., 2006a). In the present study, it was particularly interesting that a) this influence of the first letter was present for both the synaesthetes and the non-synaesthete groups, suggesting that it arises from an influence common to both groups, b) the effect of grapheme-colour congruency depended on LSA score for the association between the word and the colour. The current correlational data do not allow us to say with any certainty what the nature of the relationship is between grapheme-colour pairings and word-colour pairings. However, the commonality between the groups and the interaction between the two variables does hint at the possibility that the prototypical colours for the letters might shape the colours for the words. Children likely learn the letter ' $g$ ' well before they acquire a word like genius, and therefore it makes most sense for the letter $g$ to influence genius to green, and this association is then reflected in language patterns. But then where do the prototypical colours for letters come from? Some previous research has suggested that exposure to particular patterns early in life (e.g. the colour that letters are shown in alphabet posters or magnets) may have an enduring effect on synaesthetic associations (Witthoft, Winawer, \& Eagleman, 2015). Another possibility is that commonly-used words influence the colours for particular graphemes. For example, $a$ could be red because apples are a prototypical object beginning with the letter $a$, and are typically red. Furthermore, $b$ is blue and brown, $g$ is green, $p$ is pink, and $y$ is yellow, suggesting that colour words themselves might influence the colouring of these particular letters. However, this is clearly only at best a partial explanation, because $g$ can also be brown, $p$ blue, $y$ green, and many other letters have colours that do not appear to be related to a colour label (e.g., $e$ is green and yellow, $z$ is black). Regardless of the precise mechanism, the present results show that both synaesthetes and controls do not randomly pair letters with colours, but are instead sensitive to these shared systematicies. 
Independent of the influence of individual graphemes, words also make an independent contribution to synaesthetic colours over and above the contribution of the component letters. In a prior study investigating synaesthetic colours in response to compound words (e.g., rainbow $=$ rain + bow) in 19 synaesthetes, it was found that whether a single, unitary colour was experienced for the word, versus two colours, one for each of the subparts of the compound word, depended on the frequency of the compound word. That is, frequently-used compound words, elicited a single synaesthetic colours (Mankin, Thompson, Branigan, \& Simner, 2016). This is evidence that it is not invariably the case that lexical-colour synaesthesia can be explained via a conglomeration or competition of component pairings. Similarly, weekday colour synaesthesia has been observed without any underlying grapheme-colour synaesthesia (Simner et al., 2006b). Our results are consistent with this notion that words can influence colour in their own right. If it were only the first letter that were responsible for creating the colour associations, then LSA scores between the concept word and the associated colour would not have been a reliable predictor of concept-colour pairings. Importantly, LSA was predictive not only for synaesthetes, but also for controls in the absence of synaesthesia.

The fact that LSA scores were predictive of concept-colour pairings provides convergent evidence for the broader notion that language appears to play a powerful role in shaping our attentional and perceptual mechanisms. Also consistent with this notion is the finding that the spatial mapping of concepts in unselected samples is predicted by language use statistics (Goodhew et al., 2014; Hutchinson \& Louwerse, 2013; Louwerse, 2008; Louwerse \& Jeuniaux, 2010). This is noteworthy, given that earlier explanations for such conceptual cueing effects centred on notions such as perceptual simulation (Dudschig, De la Vega, \& Kaup, 2015; Meier \& Robinson, 2004; Zwaan \& Yaxley, 2003) derived from the embodied cognition framework (Barsalou, 1999, 2008; Gallese \& Lakoff, 2005). That is, according to this idea, words shift attention due to our perceptual experience of objects in particular locations. For example, sun shifts attention upwards in space because of our perceptual experience of the sun being above us. Such models, however, while offering plausible explanations for the mapping of concrete words (e.g., sun, sky, grass), suffer from some difficulty in explaining the spatial mapping of abstract concepts for which we do not have direct perceptual experience (e.g., dream, bliss, devil) (but see Dudschig et al., 2015). Applying the same logic to the present study, the embodied cognition framework predicts that participants might associate aircraft with 'white' because of perceptual experience of white aircraft in the world around us. However, a model of perceptual simulation struggles to explain how abstract words, such as bliss, for which we have no direct perceptual experience of a single tangible object, also come to be associated with 'blue'. The present study, therefore, further bolsters support for the importance of language in explaining systematic cognitive associations.

One could consider this creating a conundrum: how is it that language plays such an important role in a group who perhaps by definition, perceptually simulate? There is a clear way to resolve this: while language association and perceptual simulation are distinct theoretical mechanisms, they are not necessarily mutually exclusive (see Louwerse \& Jeuniaux, 2010 for evidence of independent contributions of embodiment and language processing to the spatial mapping of concepts). It is highly likely that the two interact, such as systematic patterns in language being shaped by our perceptual experience of objects and their colours in the world around us, and the reverse could also occur: learning the prototypical colour of an object via language, even without direct perceptual experience. It could be speculated that synaesthetes might even perceptually simulate the experience of learning a particular word (e.g., seeing 'Tuesday' as red because it was red on a poster when learning these words). However, even if they are conceptualised as entirely independent mechanisms, then it still leaves open the possibility that both language association and perceptual simulation contribute to concept-colour associations. Here we have not refuted perceptual simulation, instead, we have shown convincing evidence for language association.

While it plausible that some of the concept-colour associations observed here may also be influenced by perceptual simulation (e.g., grave-grey), perceptual simulation cannot explain the associations between more abstract concepts and colours (e.g., doom-black, cheerfulyellow), since we would have no direct perceptual experiences to shape these associations. The present evidence instead suggests that such associations may be acquired and transmitted by systematic tendencies embedded in language. This is also consistent with other evidence that suggests a psycholinguistic basis to synaesthetic experience in other domains such as lexical-gustatory synaesthesia (Simner, 2007; Simner \& Haywood, 2009; Ward \& Simner, 2003).

It should be acknowledged that in the present study we had to rely on synaesthetes' self-reports of synaesthetic colours experienced for the selected concept words. This is because while the validated battery (Eagleman et al., 2007) contains tests for consistency and behavioural speeded-response congruency effects for grapheme-colour synaesthesia among others, it does not have a more general lexical-colour category. This is understandable: it would not be feasible to test synaesthetes' associations for all possible words. It would be useful, however, if the battery could be extended to incorporate, for example, a test for colours for some of the more common (non-weekday) words for which synaesthetes experience colours. For the present study, however, this means that we had a two-stage process for inferring the presence of lexical-colour synaesthesia: (1) that the synaesthete successfully passed the battery grapheme-colour, and then (2) we relied on their self-reports of colours elicited by our concept words. We asked participants to leave items blank on our paper-and-pencil measure if they did not have any colours for those words, and synaesthetes did indeed leave items blank, demonstrating that they were willing to comply with this instruction. From this we infer that synaesthetes were providing us with genuine reports of their experienced colour. However, it must be acknowledged that not having behavioural indicators of reliability or congruency to verify this is a limitation of the present study.

Furthermore, we restricted the analysis to colours that had $>10$ responses associated with them. It remains to be seen how predictive language is for more uncommonly reported colours. Moreover, it should also be acknowledged that while we were able to isolate two significant predictors of concept-colour pairings in the current study, this by no means indicates that we have captured all of the factors that may influence concept-colour pairings. For instance, for the concrete words, it could be that the colour of a prototypical instance of that object influences the colour for the word. More specifically, mud might be associated brown because mud is prototypically brown. We did not have such a variable in our analysis. However, even if such a variable was a significant predictor, it would be difficult to accurately ascertain where such prototypically arises from - is it perceptual experience, or language? The soil in large parts of Australia is in fact red, producing mud that is more red than brown. However, even if one's experience is exclusively or predominately of red mud, one could still come to appreciate that mud is prototypically brown, but this may be via language (e.g. story books about brown mud) rather than perceptual experience. While these words are not on our list per se, there are a number of other examples that illustrate how prototypicality can clash with perceptual experience. Fire engines are prototypically red, whereas in Canberra (Australia's capital city) they are lime green for improved visibility in low-light conditions. Christmas prototypically calls to mind snow, despite the fact that Christmas in the southern hemisphere occurs during the height of summer, and many children in warmer parts of Australia grow up never having seen actual snow. Altogether, the point we wish to make is that while it is a limitation of the study that we did not include a variable for prototypical colour, we also wish to highlight the uncertainty in understanding the origin of such prototypicality, and the difficulty in even having a variable that accurately captures all of the diversity of individuals' unique perceptual experiences. 
It may also be the case for the abstract words that their emotional valence influences the selected colour, with more positive words producing lighter colours (such as yellow), and more negative words producing darker colours (such as blue and black). Indeed, research in other domains has shown that people automatically associate positive valence with brighter colours (Meier, Robinson, \& Clore, 2004). Our results do not preclude such a possibility, and such systematicity may even actually be encapsulated within the LSA variable. That is, language may be the specific means for instantiating such relationships, which belong to a broader category of valence and brightness. Future research can examine such possibilities.

In conclusion, the present study provides evidence that both language association statistics and prototypical colour for the first letter of each word reliably predicted the associations between concepts and colours reported by both synaesthetes and non-synaesthete controls. This suggests that language can determine fundamental perceptual processes such as the experience of synaesthetic colour, and can also influence broader associations for those who do not experience synaesthetic colours.

\section{Acknowledgements}

This research was supported by a Transdisciplinary Research Grant from the ARC Centre of Excellence for the Dynamics of Language awarded to S.C.G and E.K. (CE140100041), and an Australian Research Council (ARC) Discovery Early Career Research Award (DE140101734) awarded to S.C.G. The authors thank Stephanie Kindon for assistance with the data collection.

\section{Appendix 1}

\begin{tabular}{|c|c|c|c|c|}
\hline $\begin{array}{l}\text { Synaesthete } \\
\#\end{array}$ & Types of synaesthesia & $\begin{array}{l}\text { Consistency scores (only for } \\
\text { letter-colour) }^{\mathrm{b}}\end{array}$ & $\begin{array}{l}\mathrm{P} / \mathrm{A} \\
\text { Score }\end{array}$ & $\begin{array}{l}\text { Meet criteria for inclusion in } \\
\text { analysis? }\end{array}$ \\
\hline 1 & $\begin{array}{l}\text { Numbers } \rightarrow \text { Colour } \\
\text { Months } \rightarrow \text { Colour }\end{array}$ & & -2.2 & $\mathrm{~N}$ \\
\hline 2 & $\begin{array}{l}\text { Numbers } \rightarrow \text { Colour } \\
\text { Months } \rightarrow \text { Colour } \\
\text { Smell } \rightarrow \text { Colour } \\
\text { Personalities } \rightarrow \text { Colour } \\
\text { Emotion } \rightarrow \text { Colour }\end{array}$ & & -2.7 & $\mathrm{~N}$ \\
\hline 3 & $\begin{array}{l}\text { Numbers } \rightarrow \text { Colour } \\
\text { Letters } \rightarrow \text { Colour } \\
\text { Weekdays } \rightarrow \text { Colour } \\
\text { Months } \rightarrow \text { Colour } \\
\text { Musical chords } \rightarrow \text { Colour } \\
\text { Musical instruments } \rightarrow \text { Colour } \\
\text { Taste } \rightarrow \text { Colour } \\
\text { Smell } \rightarrow \text { Colour } \\
\text { Temperature } \rightarrow \text { Colour } \\
\text { Orgasm } \rightarrow \text { Colour } \\
\text { Emotion } \rightarrow \text { Colour } \\
\text { Mathematical theorems } \rightarrow \text { Colours, shapes, sensation }\end{array}$ & 0.68 & -2.7 & $\mathrm{Y}$ \\
\hline 4 & $\begin{array}{l}\text { Numbers } \rightarrow \text { Colour } \\
\text { Letters } \rightarrow \text { Colour } \\
\text { Weekdays } \rightarrow \text { Colour } \\
\text { Months } \rightarrow \text { Colour }\end{array}$ & 0.73 & -2.7 & $\mathrm{Y}$ \\
\hline 5 & $\begin{array}{l}\text { Numbers } \rightarrow \text { Colour } \\
\text { Letters } \rightarrow \text { Colour } \\
\text { Greek alphabet } \rightarrow \text { Colour }\end{array}$ & 0.57 & -2.0 & $\mathrm{Y}$ \\
\hline 6 & $\begin{array}{l}\text { Musical pitch } \rightarrow \text { Colour } \\
\text { Musical chords } \rightarrow \text { Colour } \\
\text { Musical instruments } \rightarrow \text { Colour } \\
\text { Taste } \rightarrow \text { Colour } \\
\text { Smell } \rightarrow \text { Colour } \\
\text { Pain } \rightarrow \text { Colour }\end{array}$ & & 0 & $\mathrm{~N}$ \\
\hline 7 & $\begin{array}{l}\text { Letters } \rightarrow \text { Colour } \\
\text { Musical chords } \rightarrow \text { Colour }\end{array}$ & 0.81 & -2.3 & $\mathrm{Y}$ \\
\hline 8 & $\begin{array}{l}\text { Numbers } \rightarrow \text { Colour } \\
\text { Letters } \rightarrow \text { Colour } \\
\text { Weekdays } \rightarrow \text { Colour } \\
\text { Months } \rightarrow \text { Colour } \\
\text { Chinese numbers } \rightarrow \text { Colour }\end{array}$ & 0.56 & -2.2 & $\mathrm{Y}$ \\
\hline $\begin{array}{l}9 \\
10\end{array}$ & $\begin{array}{l}\text { Letters } \rightarrow \text { Colour } \\
\text { Numbers } \rightarrow \text { Colour } \\
\text { Letters } \rightarrow \text { Colour } \\
\text { Weekdays } \rightarrow \text { Colour } \\
\text { Months } \rightarrow \text { Colour } \\
\text { Emotion } \rightarrow \text { Colour }\end{array}$ & $\begin{array}{l}0.85 \\
0.51\end{array}$ & $\begin{array}{l}-2 \\
-1.3\end{array}$ & $\begin{array}{l}\mathrm{Y} \\
\mathrm{Y}\end{array}$ \\
\hline 11 & $\begin{array}{l}\text { Numbers } \rightarrow \text { Colour } \\
\text { Letters } \rightarrow \text { Colour } \\
\text { Weekdays } \rightarrow \text { Colour } \\
\text { Months } \rightarrow \text { Colour } \\
\text { Chinese numbers } \rightarrow \text { Colour } \\
\text { Sequences } \rightarrow \text { Spatial locations } \\
\text { Musical pitch } \rightarrow \text { Colour } \\
\text { Musical chords } \rightarrow \text { Colour }\end{array}$ & 1.16 & 1.5 & $\mathrm{Y}$ \\
\hline
\end{tabular}


Appendix 1 (continued)

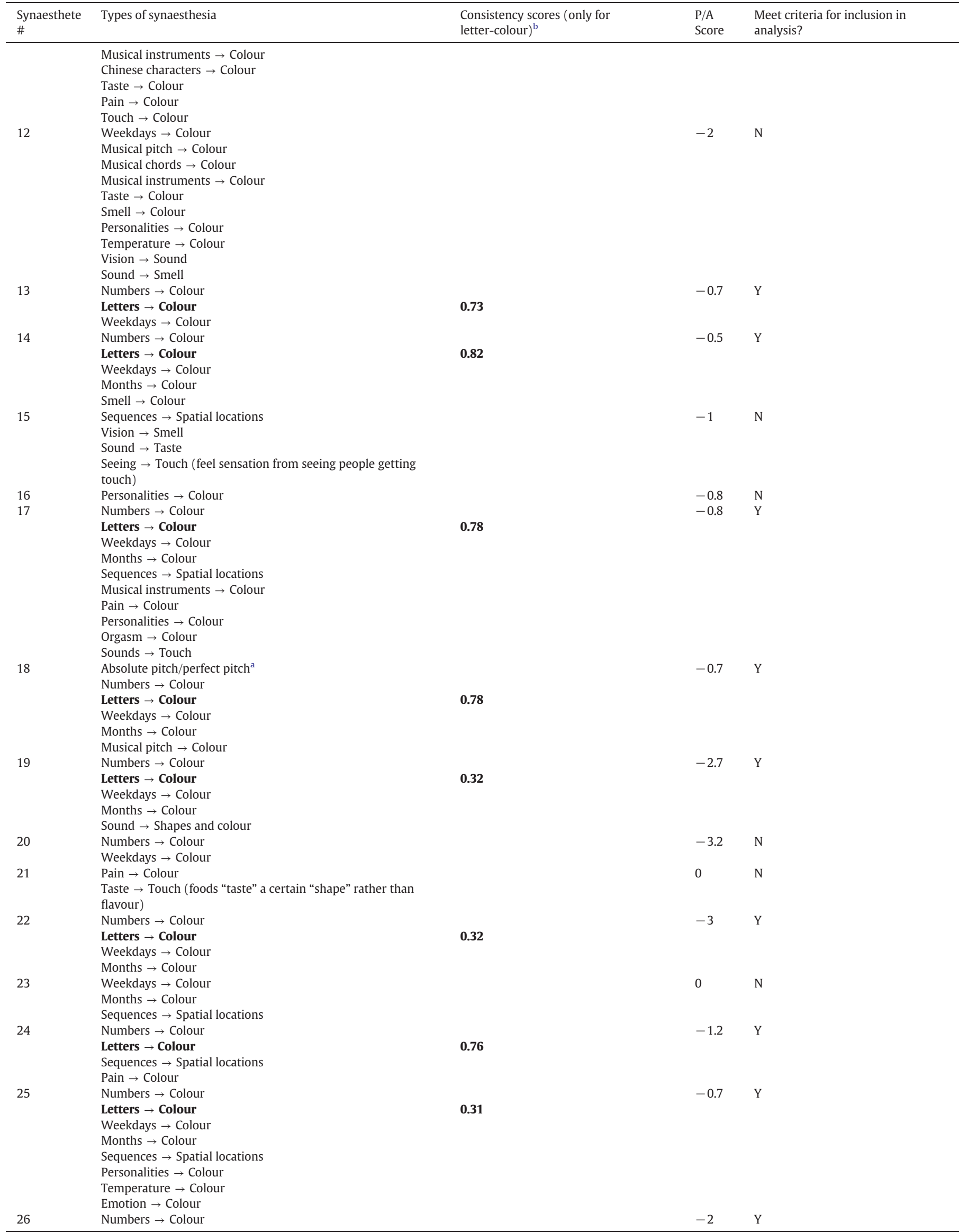


Appendix 1 (continued)

\begin{tabular}{|c|c|c|c|c|}
\hline $\begin{array}{l}\text { Synaesthete } \\
\#\end{array}$ & Types of synaesthesia & $\begin{array}{l}\text { Consistency scores (only for } \\
\text { letter-colour) }^{\mathrm{b}}\end{array}$ & $\begin{array}{l}\mathrm{P} / \mathrm{A} \\
\text { Score }\end{array}$ & $\begin{array}{l}\text { Meet criteria for inclusion in } \\
\text { analysis? }\end{array}$ \\
\hline & $\begin{array}{l}\text { Letters } \rightarrow \text { Colour } \\
\text { Weekdays } \rightarrow \text { Colour } \\
\text { Months } \rightarrow \text { Colour }\end{array}$ & 0.86 & & \\
\hline 27 & $\begin{array}{l}\text { Numbers } \rightarrow \text { Colour } \\
\text { Weekdays } \rightarrow \text { Colour } \\
\text { Months } \rightarrow \text { Colour } \\
\text { Musical instruments } \rightarrow \text { Colour } \\
\text { Smell } \rightarrow \text { Colour } \\
\text { Sound } \rightarrow \text { Taste }\end{array}$ & $\begin{array}{l}0.51 \\
0.4 \\
0.91\end{array}$ & -1.7 & $\mathrm{~N}$ \\
\hline 28 & $\begin{array}{l}\text { Letters } \rightarrow \text { Colour } \\
\text { Weekdays } \rightarrow \text { Colour }\end{array}$ & 0.49 & 0 & $\mathrm{Y}$ \\
\hline 29 & Sequences $\rightarrow$ Spatial locations & & -0.2 & $\mathrm{~N}$ \\
\hline 30 & $\begin{array}{l}\text { Absolute pitch/perfect pitch } \\
\text { Numbers } \rightarrow \text { Colour }\end{array}$ & & -1.3 & $\mathrm{Y}$ \\
\hline & $\begin{array}{l}\text { Letters } \rightarrow \text { Colour } \\
\text { Weekdays } \rightarrow \text { Colour } \\
\text { Months } \rightarrow \text { Colour }\end{array}$ & 0.85 & & \\
\hline
\end{tabular}

Inducer-concurrent pairs in bold signify the forms of synaesthesia recorded in the battery used to identify lexical-colour synaesthetes.

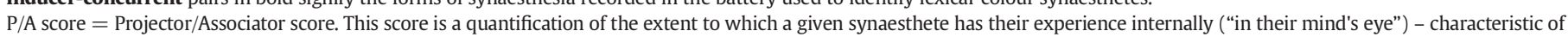

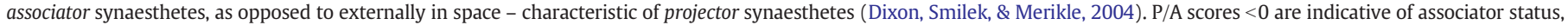
whereas scores $>0$ are indicative of projector status (Eagleman et al., 2007).

a While Absolute pitch/perfect pitch is not actually a form of synaesthesia, since the battery records it we report it here for interest.

b Consistency scores $<1$ are indicative of synaesthesia. Note that where a participant has colours for both letters and digits, the battery reports a single combined consistency value for these, and this is what is reported next to letter $\rightarrow$ colour form of synaesthesia.

\section{Appendix 2}

Categorisation decisions made about to which broader colour category synaesthetes' reports should belong.

- Moss green $\rightarrow$ green

- Sky blue $\rightarrow$ pale blue

- Light blue $\rightarrow$ pale blue

- Dark washed out pink $\rightarrow$ pink

- Navy $\rightarrow$ dark blue

- Olive green $\rightarrow$ green

- Lime green $\rightarrow$ green

- Dark green $\rightarrow$ green

- Dark purple $\rightarrow$ purple

- Maroon $\rightarrow$ dark red

- Dark brown $\rightarrow$ brown

- Beige $\rightarrow$ cream

- Faded blue $\rightarrow$ pale blue

- Light grey $\rightarrow$ grey

- Mustard $\rightarrow$ yellow, orange, and brown

- Muted red $\rightarrow$ red

Not classified:

One synaesthete reported both sun and mud as the colour "mud". It was unclear what colour this should be treated as. At first blush it might be considered brown, but since this is one of the items in the list, it seemed presumptuous to give it a colour on behalf of the participant. It was therefore not classified.

\section{Appendix 3}

Categorisation decisions made about to which broader colour category non-synaesthetes (controls) reports should belong.

- Light green $\rightarrow$ green

- Light blue $\rightarrow$ pale blue

- Navy blue $\rightarrow$ dark blue

- Light brown $\rightarrow$ brown

- Indigo $\rightarrow$ blue + purple

- Maroon $\rightarrow$ dark red

- Dark brown $\rightarrow$ brown

- Lemon yellow $\rightarrow$ yellow

- Hazy blue $\rightarrow$ blue

- Bright yellow $\rightarrow$ yellow

- Light grey $\rightarrow$ grey

- Fluorescent green $\rightarrow$ green

- Light orange $\rightarrow$ orange

- Faint green $\rightarrow$ green

- Off-white $\rightarrow$ cream

- Clay $\rightarrow$ red + brown
- Light brown $\rightarrow$ brown

- Dark $\rightarrow$ black

- Steel blue $\rightarrow$ blue, grey

- Polished steel $\rightarrow$ grey

- Cherry $\rightarrow$ dark red

- Light pink $\rightarrow$ pink

- Dark pink $\rightarrow$ pink

- Charcoal $\rightarrow$ dark grey

- Salmon $\rightarrow$ pink

- Forest green $\rightarrow$ green

- Mottled green $\rightarrow$ green

- Light purple $\rightarrow$ purple

- Army green $\rightarrow$ green
- Light yellow $\rightarrow$ yellow

- Dull green $\rightarrow$ green

- Transparent grey $\rightarrow$ grey

- Dark green $\rightarrow$ green

- Sparking yellow $\rightarrow$ yellow

- Dark yellow $\rightarrow$ yellow

- Light yellow $\rightarrow$ yellow

- Light cream $\rightarrow$ cream

- Earth brown $\rightarrow$ brown

- Sodium lights $\rightarrow$ yellow

- Light brown $\rightarrow$ brown

- Brownish $\rightarrow$ brown

- Beige $\rightarrow$ cream

- Fluorescent yellow $\rightarrow$ yellow

- Army green $\rightarrow$ green

- Sky blue $\rightarrow$ pale blue

- Soil brown $\rightarrow$ brown 
- Algae green $\rightarrow$ green

- A dirty blue $\rightarrow$ blue

- Metallic $\rightarrow$ grey

- Light pink $\rightarrow$ pink

Not classified:

Two participants reported trash as 'multicoloured'. Since this was not a colour-selective response, it was not scored. Similarly, one participant responded 'reflection of dary [sic] images' and another simply 'clear' in response to puddle. Again, these did not fit any of the above categories and were thus not scored. Furthermore, one participant responded that was miserable was 'the transparent tear colour', and one reported that doom was a 'dull colour' none of which clearly fitted the above categories and so were not scored.

\section{Appendix 4}

This shows the overall frequency in language use for each of the concept words in the Google Ngram corpus, which are expressed as frequencies given the total number of words (currently $>360$ billion words, Michel et al., 2011)

\begin{tabular}{lll}
\hline Word & Frequency $(\%)$ & Log transformed frequency \\
\hline Bliss & 0.0005602744 & -3.25 \\
Cheerful & 0.0005958327 & -3.22 \\
Happy & 0.0064319210 & -2.19 \\
Joy & 0.0033487511 & -2.48 \\
Victory & 0.0029709706 & -2.53 \\
Positive & 0.0108060508 & -1.97 \\
Aircraft & 0.0025558331 & -2.59 \\
Genius & 0.0014736543 & -2.83 \\
Peak & 0.0029772683 & -2.53 \\
Sun & 0.0086363108 & -2.06 \\
Star & 0.0045142252 & -2.35 \\
Tower & 0.0021202159 & -2.67 \\
Unhappy & 0.0010516836 & -2.98 \\
Sorrow & 0.0010806500 & -2.97 \\
Negative & 0.0088178458 & -2.05 \\
Miserable & 0.0008943195 & -3.05 \\
Doom & 0.0003548769 & -3.45 \\
Bleak & 0.0003332908 & -3.48 \\
Underground & 0.0013496220 & -2.87 \\
Underworld & 0.0002743384 & -3.56 \\
Grave & 0.0022146117 & -2.65 \\
Mud & 0.0013400655 & -2.87 \\
Trash & 0.0005697144 & -3.24 \\
Puddle & 0.0001217760 & -3.91 \\
\hline
\end{tabular}

\section{Appendix 5}

\begin{tabular}{|c|c|c|c|}
\hline & Log frequency & AoA & Imageability \\
\hline LSA & -0.123 & -0.135 & -0.123 \\
\hline Imageability & 0.102 & $-0.422^{*}$ & \\
\hline AoA & -0.287 & & \\
\hline
\end{tabular}

* $p<0.05$ (2-tailed).

\section{Appendix 6}

Model used in Experiment 1A. model $=\operatorname{lmer}\left(\right.$ response $\sim(\text { LSA }+ \text { gcc })^{\wedge} 2+\log$ freq + imageability + AoA $+(1 \mid$ concept $)+(1 \mid$ colour $)$, data $=$ data).

Model used in Experiment 1B. model $=\operatorname{lmer}\left(\right.$ response $\sim(\text { LSA }+ \text { gcc })^{\wedge} 2+\log$ freq + imageability + AoA $+(1 \mid$ concept $)+(1 \mid$ colour $)+(1+$ gcc $\mid$ concept $)+(1+$ gcc $\mid$ colour $)+(1+\mathrm{LSA}+$ AoA + image $\mid$ concept $)$, data $=$ data $)$

Overall model comparing groups: model $=\operatorname{lmer}\left(\right.$ resp $\sim(\text { group }+ \text { LSA }+ \text { gcc })^{\wedge} 3+\log$ freq + imageability + AoA $+(1 \mid$ concept $)+(1 \mid$ colour $)+(1+$ group $\mid$ concept $)+(1+\mathrm{LSA} \mid$ concept $)$, data $=$ data $)$

\section{Appendix 7}

Full model output for overall analysis.

\begin{tabular}{|c|c|c|c|}
\hline & $\beta$ & $\operatorname{SE}(\beta)$ & $t$ \\
\hline Intercept & 0.08 & 0.01 & $9.11^{*}$ \\
\hline Group & -0.002 & 0.01 & -0.22 \\
\hline LSA & 0.35 & 0.1 & $3.43^{*}$ \\
\hline GCC & 0.02 & 0.02 & 1.36 \\
\hline
\end{tabular}


Appendix 5 (continued)

\begin{tabular}{|c|c|c|c|}
\hline & $\beta$ & $\operatorname{SE}(\beta)$ & $t$ \\
\hline Log freq & 0.01 & 0.01 & 0.70 \\
\hline Imageability & -0.004 & 0.005 & -0.80 \\
\hline AoA & 0.004 & 0.003 & 1.30 \\
\hline Group X LSA & -0.18 & 0.11 & -1.70 \\
\hline Group X GCC & 0.012 & 0.03 & 0.49 \\
\hline LSA X GCC & 0.80 & 0.23 & $3.52^{*}$ \\
\hline Group X LSA X GCC & -0.43 & 0.32 & -1.36 \\
\hline
\end{tabular}

$* \mathrm{p}<.05$

\section{References}

Bargary, G., \& Mitchell, K. J. (2008). Synaesthesia and cortical connectivity. Trends in Neurosciences, 31(7), 335-342. http://dx.doi.org/10.1016/j.tins.2008.03.007.

Barnett, K. J., Feeney, J., Gormley, M., \& Newell, F. N. (2009). An exploratory study of linguistic-colour associations across languages in multilingual synaesthetes. The Quarterly Journal of Experimental Psychology, 62(7), 1343-1355. http://dx.doi.org/10. 1080/17470210802483461.

Baron-Cohen, S., Harrison, J., Goldstein, L. H., \& Wyke, M. (1993). Coloured speech perception: is synaesthesia what happens when modularity breaks down? Perception, 22(4), 419-426.

Barr, D. J., Levy, R., Scheepers, C., \& Tily, H. J. (2013). Random effects structure for confirmatory hypothesis testing: Keep it maximal. Journal of Memory and Language, 68(3), 255-278. http://dx.doi.org/10.1016/j.jml.2012.11.001.

Barsalou, L. W. (1999). Perceptual symbol systems. Behavioral and Brain Sciences, 22(4), 577-660. http://dx.doi.org/10.1017/S0140525X99002149.

Barsalou, L. W. (2008). Grounded cognition. Annual Review of Psychology, 59, 617-645. http://dx.doi.org/10.1146/annurev.psych.59.103006.093639.

Bates, D., \& Maechler, M. (2010). lme4: Linear mixed-effects models using S4 classes. From http://CRAN.R-project.org/package $=$ lme4

Boroditsky, L., Fuhrman, O., \& McCormick, K. (2011). Do English and Mandarin speakers think about time differently? Cognition, 118(1), 126-132. http://dx.doi.org/10.1016/ j.cognition.2010.09.010.

Brang, D., Hubbard, E., Coulson, S., Huang, M., \& Ramachandran, V. (2010). Magnetoencephalography reveals early activation of V4 in grapheme-color synesthesia. NeuroImage, 53(1), 268-274. http://dx.doi.org/10.1016/j.neuroimage.2010.06. 008.

Brang, D., Rouw, R., Ramachandran, V., \& Coulson, S. (2011). Similarly shaped letters evoke similar colors in grapheme-color synesthesia. Neuropsychologia, 49(5), 1355-1358. http://dx.doi.org/10.1016/j.neuropsychologia.2011.01.002.

Brysbaert, M., Warriner, A. B., \& Kuperman, V. (2014). Concreteness ratings for 40 thousand generally known English word lemmas. Behavior Research Methods, 46(3), 904-911. http://dx.doi.org/10.3758/s13428-013-0403-5.

Chasteen, A. L., Burdzy, D. C., \& Pratt, J. (2010). Thinking of God moves attention. Neuropsychologia, 48(2), 627-630. http://dx.doi.org/10.1016/j.neuropsychologia. 2009.09.029.

Dixon, M. J., Smilek, D., \& Merikle, P. M. (2004). Not all synaesthetes are created equal Projector versus associator synaesthetes. Cognitive, Affective $\mathcal{E}$ Behavioral Neuroscience, 4(3), 335-343. http://dx.doi.org/10.3758/CABN.4.3.335.

Dudschig, C., De la Vega, I., \& Kaup, B. (2015). What's up? Emotion-specific activation of vertical space during language processing. Acta Psychologica, 156, 143-155. http:/ dx.doi.org/10.1016/j.actpsy.2014.09.015.

Dudschig, C., Souman, J., Lachmair, M., de la Vega, I., \& Kaup, B. (2013). Reading "sun" and looking up: The influence of language on saccadic eye movements in the vertical dimension. Plos ONE, 8(2). http://dx.doi.org/10.1371/journal. pone.0056872.

Dumais, S. T. (2005). Latent semantic analysis. Annual Review of Information Science and Technology, 38(1), 188-230. http://dx.doi.org/10.1002/aris.1440380105.

Eagleman, D. M., Kagan, A. D., Nelson, S. S., Sagaram, D., \& Sarma, A. K. (2007). A standardized test battery for the study of synesthesia. Journal of Neuroscience Methods, 159(1), 139-145. http://dx.doi.org/10.1016/j.jneumeth.2006.07.012.

Estes, Z., Verges, M., \& Adelman, J. S. (2015). Words, objects, and locations: Perceptual matching explains spatial interference and facilitation. Journal of Memory and Language, 84, 167-189. http://dx.doi.org/10.1016/j.jml.2015.06.002.

Estes, Z., Verges, M., \& Barsalou, L. W. (2008). Head up, foot down: Object words orient attention to the objects' typical location. Psychological Science, 19(2), 93-97. http:/ dx.doi.org/10.1111/j.1467-9280.2008.02051.x.

Gallese, V., \& Lakoff, G. (2005). The brain's concepts: The role of the sensory-motor system in conceptual knowledge. Cognitive Neuropsychology, 22(3/4), 455-479. http:// dx.doi.org/10.1080/02643290442000310.

Galton, F. (1880). Visualized numerals. Nature, 21, 252-256

Goodhew, S. C., \& Kidd, E. (2016). The conceptual cueing database: Rated items for the study of the interaction between language and attention. Behavior Research Methods, 48, 1004-1007. http://dx.doi.org/10.3758/s13428-015-0625-9.

Goodhew, S. C., McGaw, B., \& Kidd, E. (2014). Why is the sunny side always up? Explaining the spatial mapping of concepts by language use. Psychonomic Bulletin $E$ Review, 21(5), 1287-1293. http://dx.doi.org/10.3758/s13423-014-0593-6.

Gozli, D. G., Chasteen, A. L., \& Pratt, J. (2013a). The cost and benefit of implicit conceptual cues for visual attention. Journal of Experimental Psychology: General. http://dx.doi. org/10.1037/a0030362.
Gozli, D. G., Chow, A., Chasteen, A. L., \& Pratt, J. (2013b). Valence and vertical space: Saccade trajectory deviations reveal metaphorical spatial activation. Visual Cognition, 21(5), 628-646. http://dx.doi.org/10.1080/13506285.2013.815680.

Hutchinson, S., \& Louwerse, M. M. (2013). Language statistics explain the spatial-numerical association of response codes. Psychonomic Bulletin \& Review. http://dx.doi.org/ 10.3758/s13423-013-0492-2

Jones, C., Gray, M., Minati, L., Simner, J., Critchley, H., \& Ward, J. (2011). The neural basis of illusory gustatory sensations: Two rare cases of lexical-gustatory synaesthesia. Journal of Neuropsychology, 5(2), 243-254. http://dx.doi.org/10.1111/j.1748-6653.2011.02013. $\mathrm{x}$.

Kuperman, V., Stadthagen-Gonzalez, H., \& Brysbaert, M. (2012). Age-of-acquisition ratings for 30,000 English words. Behavior Research Methods, 44(4), 978-990. http:// dx.doi.org/10.3758/s13428-012-0210-4.

Landauer, T. K., Foltz, P. W., \& Darrell, L. (1998). An introduction to latent semantic analysis. Discourse Processes, 25, 259-284. http://dx.doi.org/10.1080/ 01638539809545028.

Linck, J. A., \& Cunnings, I. (2015). The utility and application of mixed-effects models in second language research. Language Learning, 65(S1), 185-207. http://dx.doi.org/10. 1111/lang.12117.

Louwerse, M. M. (2008). Embodied relations are encoded in language. Psychonomic Bulletin \& Review, 15(4), 838-844. http://dx.doi.org/10.3758/PBR.15.4.838.

Louwerse, M. M., \& Jeuniaux, P. (2010). The linguistic and embodied nature of conceptual processing. Cognition, 114(1), 96-104. http://dx.doi.org/10.1016/j.cognition.2009.09. 002

Mankin, J. L., Thompson, C., Branigan, H. P., \& Simner, J. (2016). Processing compound words: Evidence from synaesthesia. Cognition, 150, 1-9. http://dx.doi.org/10.1016/j. cognition.2016.01.007.

Mattingley, J. B., Rich, A. N., Yelland, G., \& Bradshaw, J. L. (2001). Unconscious priming eliminates automatic binding of colour and alphanumeric form in synaesthesia. Nature, 410(6828), 580-582. http://dx.doi.org/10.1038/35069062.

Meier, B. P., \& Robinson, M. D. (2004). Why the sunny side is up: Associations between affect and vertical position. Psychological Science, 15(4), 243-247. http://dx.doi.org/ 10.1111/j.0956-7976.2004.00659.x.

Meier, B. P., Robinson, M. D., \& Clore, G. L. (2004). Why good guys wear white: Automatic inferences about stimulus valence based on brightness. Psychological Science, 15(2), 82-87. http://dx.doi.org/10.1111/j.0963-7214.2004.01502002.x.

Michel, J. B., Shen, Y. K., Aiden, A. P., Veres, A., Gray, M. K., Pickett, J. P., ... Google Books, T. (2011). Quantitative analysis of culture using millions of digitized books. Science, 331(6014), 176-182. http://dx.doi.org/10.1126/science.1199644.

Novich, S., Cheng, S., \& Eagleman, D. M. (2011). Is synaesthesia one condition or many? A large-scale analysis reveals subgroups. Journal of Neuropsychology, 5(2), 353-371. http://dx.doi.org/10.1111/j.1748-6653.2011.02015.x.

Ramachandran, V. S., \& Hubbard, E. M. (2001). Synaesthesia-A window into perception, thought and language. Journal of Consciousness Studies, 8(12), 3-34

Rich, A. N., Bradshaw, J. L., \& Mattingley, J. B. (2005). A systematic, large-scale study of synaesthesia: implications for the role of early experience in lexical-colour associations. Cognition, 98(1), 53-84. http://dx.doi.org/10.1016/j.cognition.2004.11.003.

Rothen, N., Seth, A. K., Witzel, C., \& Ward, J. (2013). Diagnosing synaesthesia with online colour pickers: Maximising sensitivity and specificity. Journal of Neuroscience Methods, 215(1), 156-160. http://dx.doi.org/10.1016/j.jneumeth. 2013.02.009.

Santiago, J., Lupianez, J., Perez, E., \& Funes, M. J. (2007). Time (also) flies from left to right. Psychonomic Bulletin \& Review, 14(3), 512-516. http://dx.doi.org/10.3758/ BF03194099.

Simner, J. (2007). Beyond perception: Synaesthesia as a psycholinguistic phenomenon. Trends in Cognitive Sciences, 11(1), 23-29. http://dx.doi.org/10.1016/j.tics. 2006.10.010.

Simner, J., Glover, L., \& Mowat, A. (2006a). Linguistic determinants of word colouring in grapheme-colour synaesthesia. Cortex: A Journal Devoted to the Study of the Nervous System and Behavior, 42(2), 281-289. http://dx.doi.org/10.1016/S00109452\%2808\%2970353-8.

Simner, J., \& Haywood, S. L. (2009). Tasty non-words and neighbours: the cognitive roots of lexical-gustatory synaesthesia. Cognition, 110(2), 171-181. http://dx.doi.org/10. 1016/j.cognition.2008.11.008.

Simner, J., Mulvenna, C., Sagiv, N., Tsakanikos, E., Witherby, S. A., Fraser, C., \& Ward, J. (2006b). Synaesthesia: The prevalence of atypical cross-modal experiences. Perception, 35(8), 1024-1033.

Simner, J., Ward, J., Lanz, M., Jansari, A., Noonan, K., Glover, L., \& Oakley, D. A. (2005). Nonrandom associations of graphemes to colours in synaesthetic and non-synaesthetic populations. Cognitive Neuropsychology, 22(8), 1069-1085. http://dx.doi.org/10. $1080 / 02643290500200122$. 
Ward, J., \& Simner, J. (2003). Lexical-gustatory synaesthesia: linguistic and conceptual factors. Cognition, 89(3), 237-261.

Ward, J., Simner, J., \& Auyeung, V. (2005). A comparison of lexical-gustatory and grapheme-colour synaesthesia. Cognitive Neuropsychology, 22(1), 28-41. http://dx.doi. org/10.1080/02643290442000022.

Weger, U. W., \& Pratt, J. (2008). Time flies like an arrow: Space-time compatibility effects suggest the use of a mental timeline. Psychonomic Bulletin E Review, 15(2), 426-430. http://dx.doi.org/10.3758/PBR.15.2.426.
Witthoft, N., Winawer, J., \& Eagleman, D. M. (2015). Prevalence of learned graphemecolor pairings in a large online sample of synesthetes. Plos ONE, 10(3), e0118996. http://dx.doi.org/10.1371/journal.pone.0118996.

Zwaan, R. A., \& Yaxley, R. H. (2003). Spatial iconicity affects semantic relatedness judgements. Psychonomic Bulletin \& Review, 10(4), 954-958. http://dx.doi.org/10.3758/ BF03196557. 